\title{
UNUSUAL PRESENTATION OF A GIANT EPIDERMOID CYST IN SCALP REGION- A CASE REPORT
}

\author{
Honey Shukla1, Anil Singh Chauhan², Shweta Shah ${ }^{3}$
}

${ }^{1}$ Senior Lecturer, Department of Oral and Maxillofacial Surgery, Modern Dental College and Research Centre, Indore, Madhya Pradesh. ${ }^{2}$ Senior Lecturer, Department of Oral and Maxillofacial Surgery, Modern Dental College and Research Centre, Indore, Madhya Pradesh. 3Junior Resident, Department of Oral and Maxillofacial Surgery, Modern Dental College and Research Centre, Indore, Madhya Pradesh.

HOW TO CITE THIS ARTICLE: Shukla H, Chauhan AS, Shah S. Unusual presentation of a giant epidermoid cyst in scalp region- a case report. J. Evolution Med. Dent. Sci. 2017;6(81):5739-5742, DOI: 10.14260/jemds/2017/1244

\section{PRESENTATION OF CASE}

An otherwise ordinarily occurring epidermoid cyst in most of the cases is considered as a benign and harmless one.(1) It is of an epidermal origin and it usually presents itself on body parts such as the scalp, trunk and face.(2)

Although, frequently encountered and detected in surgical practice, its appearance as a giant epidermoid cyst on the scalp is rare.(1) These growths are often neglected, but when they force the patient to seek help medically they are most of the times surgically excised.

In the following case report, one such rare case report of a giant epidermoid cyst on the scalp is presented.

A 42-year-old female reported to the Department of Oral and Maxillofacial Surgery of our institution complaining of a large painful swelling on right side of the scalp behind the ear (Fig. 1).

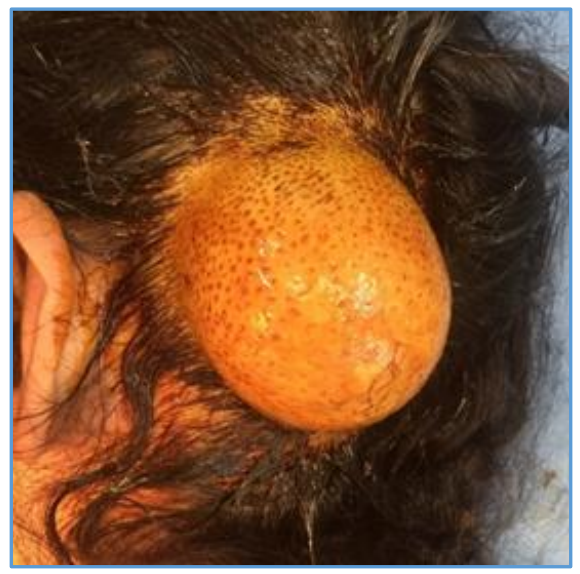

Figure 1

On taking a thorough history it was revealed that the patient first noticed the swelling 1 year back which was smaller in size then, but gradually increased to the present size and became painful since 1 week.

There was history of associated hair loss on the overlying skin.

There was no relevant past medical and dental history, also no similar family history was present.

'Financial or Other Competing Interest': None.

Submission 13-08-2017, Peer Review 27-09-2017,

Acceptance 04-10-2017, Published 09-10-2017.

Corresponding Author:

Dr. Honey Shukla,

1 Shriram Nagar Colony Dharnaka,

Mhow, Indore-453441,

Madhya Pradesh.

E-mail: honeysharma.mds@gmail.com

DOI: $10.14260 /$ jemds $/ 2017 / 1244$

\section{DIFFERENTIAL DIAGNOSIS}

Sebaceous glands are the glands present in the skin, which secrete sebum. They are usually associated with the hair follicles. When the opening of the gland is obstructed, it leads to the collection of the secretion inside the gland and leads to the formation of the cysts.

Most of the times epidermoid cysts grow slowly and form out of the sebaceous glands. They may occur or develop in case the gland or duct is damaged or blocked.(3) Most of the times, this occurs due to trauma to that particular area. The trauma could be a scratch, a surgical wound or a skin condition. The cyst is usually noticeable weeks or months after the occurrence of the trauma. Various other causes of the sebaceous cyst include:

- Damage to the cells during surgery.

- A misshapen or a blocked duct.

- Genetic conditions like Gardner's Syndrome, Basal Cell Nevus Syndrome.

Hence, after taking a detailed and thorough past medical and dental history along with an immaculate clinical viewing of the cyst, the following differential diagnosis of the swelling was made. The differential diagnosis of the soft lumps on the scalp includes:

1. Benign lipomas.

2. Spindle cell lipomas.

3. Hibernomas.

4. Epidermoid cysts.

5. Sebaceous cysts.

\section{CLINICAL DIAGNOSIS}

A clinical diagnosis was made after conducting a detailed and thorough examination of the swelling, i.e.

A detailed general and systemic examination was conducted, which resulted to be unremarkable.

Local examination revealed a single large swelling on the scalp behind the ear measuring about $3 \mathrm{~cm} \mathrm{x} 4 \mathrm{~cm}$ in diameter (Fig. 2).

On palpation, it was seen that the swelling was tender with presence of erythema, fixed to the skin but free from the underlying structures.

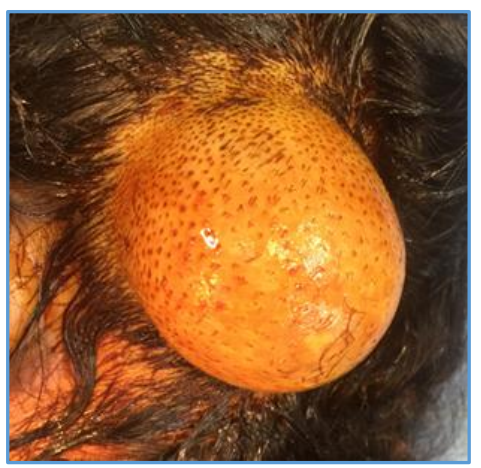

Figure 2 
It was dome shaped, soft in consistency, non-fluctuant, non-pulsatile, the temperature of the overlying skin was normal. There was absence of cervical lymphadenopathy.

Hence, after a detailed evaluation of the swelling a clinical diagnosis of the swelling being a sebaceous cyst/ benign lipoma/ epidermoid cyst was reached upon.

\section{PATHOLOGICAL DISCUSSION}

Sebaceous cysts are true cysts, which develops from a ruptured pilo-sebaceous follicle.

The cysts usually contain keratin and lipid and a foul odour in relation with these cysts is usually associated with the relative fat content, bacterial infection or decomposition.(4)

It can also be called an epidermoid cyst more correctly, because it is lined by stratified squamous epithelium.(4)

On rupturing it discharges soft, yellow keratin material and scarring makes the excision all the more difficult.

For the histopathological reports, there are two school of thoughts, i.e. some surgeons believe that the whole specimen should be sent for the examination because the giant cyst carries a potency for malignant transformation, while some believe that because it is rarely associated with such transformations only the atypical appearing lesion should be sent for histopathological examination.(5)

\section{In the above mentioned case}

A Fine Needle Aspiration was carried out using a wide bore needle, which revealed presence of cheesy material (Fig. 3, Fig. 4).

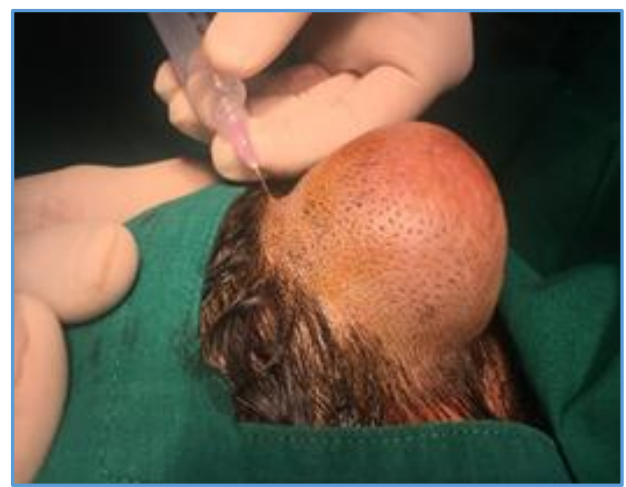

Figure 3

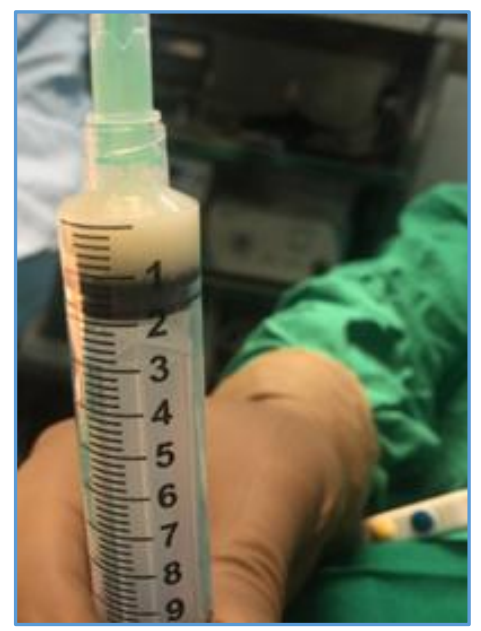

Figure 4
In the above case, we have sent the whole specimen along with the cystic contents which was aspirated prior to the surgery.

The histopathology report further confirmed our clinical diagnosis of the lesion being an epidermoid cyst with no further malignant transformation.

\section{DISCUSSION OF MANAGEMENT}

There are various techniques for treating large sebaceous cysts which include:

1. Dissection method-complete excision of the cyst.

2. Incision- avulsion method.

3. Minimal excision technique.

Complete excision though leaves a large tissue defect, but leads to complete removal of the lesion. In the above presented case, we had gone for a complete excision because in the minimal excision technique a small incision is made and the cystic contents along with the cyst are expressed by vigorous finger compression. (6)

A punch biopsy instrument can also be used for making a small incision.(7)

Inflamed cysts are difficult to excise, hence it is always recommended to delay the surgery till the inflammation subsides.(8),(9)

\section{SURGICAL PROCEDURE}

Materials and Methods

Equipment and Armamentarium

- Sterile gloves and mask (disposable).

- Gauze soaked in povidone-iodine solution.

- Local anaesthetic solution 2\% lignocaine with 1:80,000 adrenaline.

- $2 \mathrm{~mL}$ and $5 \mathrm{~mL}$ disposable syringe.

- Blade no. 10 attached in a BP handle.

- 2 small and 2 large haemostats.

- Bipolar Electrocautery.

- 2 Adson forceps.

- 2 Allis forceps.

- 2 needle holders.

- 1 suture cutting scissor.

- Suture materials (3-0 vicryl and 3-0 ethilon).

\section{SURGICAL PROCEDURE}

Under general anaesthesia and following all the aseptic measures the patient was scrubbed, painted and draped. An incision line was marked circumferentially around the cyst and local anaesthesia was administered to the skin overlying the cyst and the tissues to the side and beneath the cyst. A no. 10 blade was used to make a circumferential incision (Fig. 5). The skin was lifted from both the sides dissecting all the sides of the cystic wall (Fig. 6). 


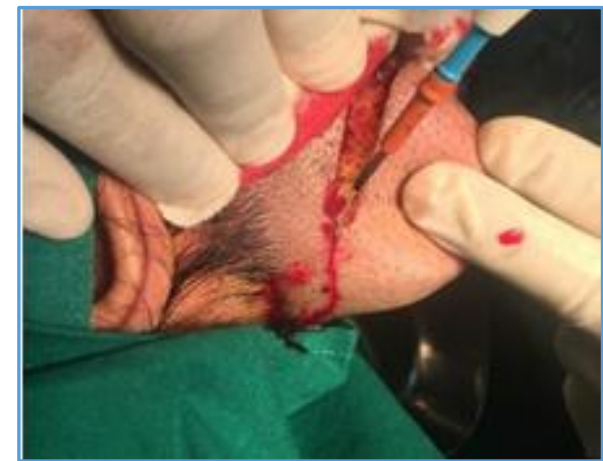

Figure 5

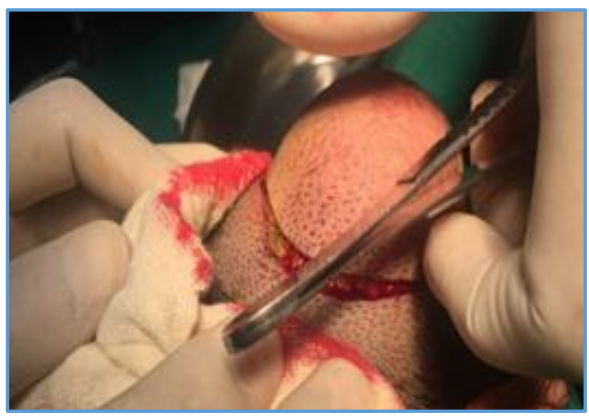

Figure 6

The cystic lining was exposed and the sac was separated from the overlying skin.

While separating the sac (Fig. 7), the lining ruptured leading to the draining of the cystic fluid i.e. the cheesy material with a rancid odor, which was further cleaned using gauze pieces (Fig. 8).

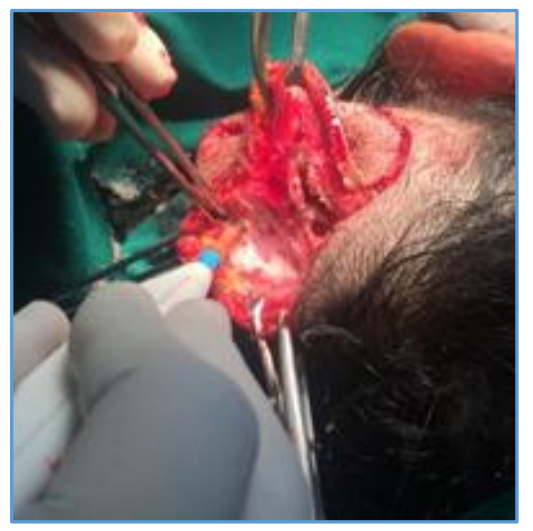

Figure 7

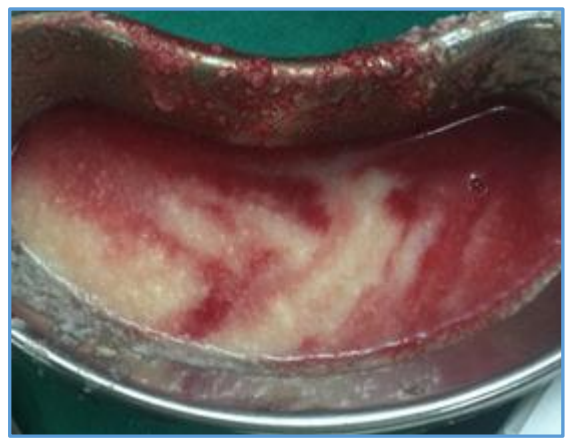

Figure 8
The empty sac was then completely excised along with the overlying adherent skin (Fig. 9) and haemostasis was achieved using electrocautery and local styptics (Fig. 10).

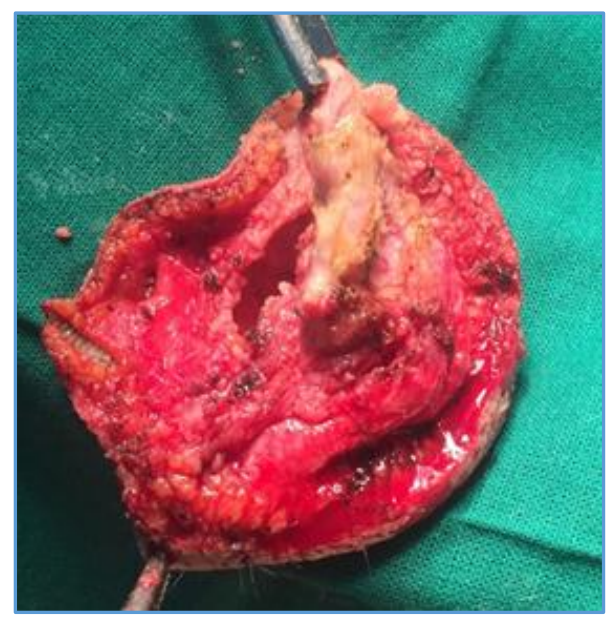

Figure 9

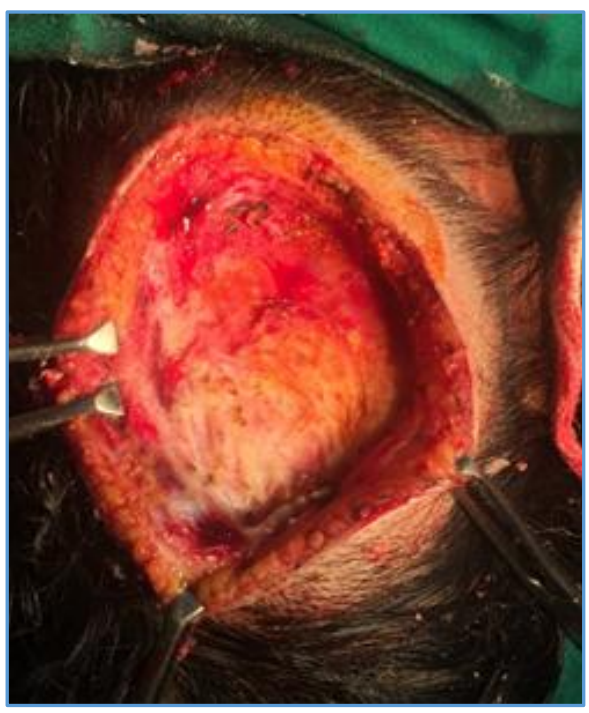

Figure 10

A 2-layer suturing was then carried out using 3-0 vicryl and 2-0 ethilon (Fig. 11) and the dressing was placed.

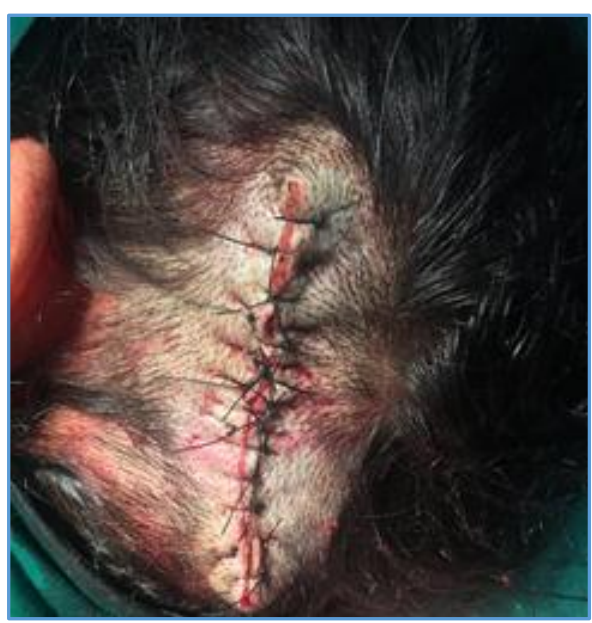

Figure 11 
Thereafter, the sutures were removed on the $7^{\text {th }}$ day and patient was then followed up for a month. There were no fresh complaints, the healing was uneventful.

\section{FINAL DIAGNOSIS}

The cysts associated with the sebaceous glands are called sebaceous cysts. It is therefore a type of a retention cyst. It can also be called an epidermoid cyst more correctly, because it is lined by stratified squamous epithelium.(4) The cyst most commonly occurs in areas of the body like face, scalp and scrotum. It is dome shaped and firm to fluctuant. It usually is filled with keratin, lipids and cellular debris.(4)

A giant sebaceous cyst rarely occurs and carries more chances of getting converted into a malignancy.(10) Different malignancies which can occur in the giant sebaceous cyst are squamous cell carcinoma, basal cell carcinoma and melanoma.(11)

After taking a thorough medical and dental history along with a detailed general and local examination, the painful swelling was differentially diagnosed to be a benign lipoma, a sebaceous cyst, an epidermoid cyst or a spindle cell lipoma.

Upon thoroughly clinically examining the swelling further, the diagnosis reached towards the lesion being an epidermoid cyst or a benign lipoma.

After sending the cheesy aspirate, which was obtained from the swelling before the surgery with the help of fine needle aspiration technique using a wide bore needle for histopathological examination, the reports confirmed it to be an epidermoid cyst with no further malignant transformation as the cyst is lined with stratified squamous epithelium with no dysplastic features, hence ruling out the possibility of a benign lipoma.

Hence, after all the history taking and examinations the final diagnosis of the painful swelling was confirmed to be an epidermoid cyst.

From the above given case report, it can hence be concluded that an epidermoid cyst which usually is asymptomatic and is otherwise neglected needs attention and surgical excision when it is large, gets infected and presents itself as a painful swelling.

\section{REFERENCES}

[1] Gross S. Sebaceous cysts correlation of clinical and pathological diagnoses in three hundred cases. J Am Med Assoc 1953;152(9):813-4.

[2] Singla A, Singh M, Singla S. Multiple giant sebaceous cysts of scalp. J Clin Diagn Res 2015;9(11):1-2.

[3] Zuber TJ. Minimal excision technique for epidermoid (sebaceous) cysts. Am Fam Physician 2002;65(7):1409-12.

[4] Phukan JP, Sinha A, Pal S, et al. Cytodiagnosis of epidermoid cyst of the upper lip: a common lesion in an uncommon site. J Lab Physicians 2014;6(1):60-2.

[5] Apollos JR, Ekatah GE, Ng GS, et al. Routine histological examination of epidermoid cysts: to send or not to send? Ann Med Surg (Lond) 2017;13:24-8.

[6] Kudejko J. Treatment of noninfectious sebaceous cysts by the pressing method. Arch Dermatol 1970;101(3):370-1.

[7] Wu H, Wang S, Wu L, et al. A new procedure for treating a sebaceous cyst: removal of the cyst content with a laser punch and the cyst wall with a minimal postponed excision. Aesthetic Plast Surg 2009;33(4):597-9.

[8] Sempowski IP. Sebaceous cysts. Can Fam Physician 2006;52(3):315-7.

[9] Khafif RA, Attie JN. One-stage excision of infected sebaceous cysts. Arch Surg 1969;98(1):117-8.

[10] Ziadi S, Trimeche M, Hammedi F, et al. Squamous cell carcinoma arising from an epidermal inclusion cyst: a case report. N Am J Med Sci 2010;2(1):46-7.

[11] Peden JC. Carcinoma developing in sebaceous cysts. Ann Surg 1948;128(6):1136-47. 